\section{Pollen morphological analysis of papaya (Carica papaya L.)}

\author{
Yanfang Zhang ${ }^{1}$, Yueming Xiong ${ }^{1 *}$, Youjie Liu ${ }^{1}$ and Xiongfeng \\ Huang $^{1}$
}

\begin{abstract}
There is little information on pollen morphological analysis of papaya cultivars with different flesh color and origins. We observed pollen morphological characters of 17 papaya cultivars through scanning electron microscopy. The results showed that papaya pollen grains were monads, tricolporate, and small and medium-sized. The pollen grains were oblate-spheroidal to spheroidal. Foveolate, reticulate, and fossulate exine ornamentation were observed. Colpi width had maximum coefficient of variation of 25\%; Shannon diversity index of all qualitative characters reached over 0.8. Using cluster analysis, 17 papaya cultivars were divided into three groups; there was no relationship between flesh colors and origins. The study findings suggest that pollen morphological analysis is valuable to provide references for breeding and genetic improvement of papaya.
\end{abstract}

Keywords: Cluster analysis, genetic diversity, papaya, pollen, scanning electron microscope

\section{INTRODUCTION}

Papaya (Carica papaya L.) is an important fruit widely distributed in tropical and subtropical areas (Kumari and Mishra 2019). It can be used in the food industry and medical and cosmetic products owing to its nutrients and phytochemicals (Srivastava et al. 2016, Jurandi et al. 2018). The growing demand for papaya in the international market evokes an increased concern regarding its genetic resource, breeding and s and improvement (Luz et al. 2018).

Genetic resources are the foundation materials for crop breeding and genetic improvement. Researchers investigating the genetic resources of papaya have highly focused on phenotypic and agronomic traits (Pan et al. 2011, Wu et al. 2011, Xiong et al. 2015, Xiong et al. 2019). Most phenotypical and agronomic traits are highly influenced by the environment (Damasceno Junior et al. 2018). Studies on molecular markers of papaya genetic resources have also been reported, such as RAPD (Huang et al. 2007), AFLP (van Droogenbroeck et al. 2002), SCAR (Liao et al. 2017), SRAP and ScoT (Cai et al. 2014), ISSR (Palei et al. 2019), SSR (Fang et al. 2016). Ming et al. (2012) reported the draft genome of transgenic papaya; this had a profound impact on papaya improvement. These molecular markers and genomic analysis improved our understanding of papaya genetic resources. However, their high costs constitute a drawback (Singh et al. 2020). Moreover, accurate operation of the above techniques and deep understanding of the complicated theory are warranted.
Crop Breeding and Applied Biotechnology 21(3): e37122138, 2021 Brazilian Society of Plant Breeding. Printed in Brazil http://dx.doi.org/10.1590/198470332021v21n3a47 


\section{Y Zhang et al.}

Microscopical techniques using a scanning electron microscope (SEM) have become popular to assess micromorphology of plants (Ayaz et al. 2020, Lynn et al. 2020, Silva-Fourny et al. 2020, Gul et al. 2021, Ullah et al. 2021). Erdtman (1952) first described the pollen grains of papaya. Fisher (1980) observed pollen of several unnamed papaya cultivars of Latin American origin. Santos et al. (2008) described the pollen grain development of papaya cv. 'Solo'. Phuangrat et al. (2013) observed pollen of the Thai papaya cultivar 'Khak Nual'. Zini et al. (2018) studied pollen morphological characters of two papaya germplasms from Argentina. However, in all of these studies, there was little information on the pollen morphology of papaya cultivars with different flesh colors and origins.

Pollen can transmit genetic information of male gametes to a new generation (Payamnoor et al. 2019). Pollen size, shape, type, grain number, aperture structure and position, and exine ornamentation are highly diverse (Halbritter et al. 2018). Pollen morphological analysis using an SEM is cost-effective, is not or rarely affected by the environment, and yields high-resolution images that are visible and easy to understand. The objectives of this study were to examine pollen morphological characters of 17 papaya cultivars of different flesh colors and origins through SEM, investigate pollen diversity, and analyze genetic relations of 17 cultivars.

\section{MATERIAL AND METHODS}

We collected pollen from staminate floral flowers of 17 papaya cultivars (Table 1) cultivated in Fujian Province, China for SEM observation between 2019 and 2020 in blooming buds. Pollen was fixed in 5\% glutaraldehyde for four hours, washed three times with $0.1 \mathrm{~mol} \mathrm{~L}^{-1}$ PBS, fixed with $1 \%$ osmic acid for four hours, and eventually washed three times with distilled water. Different ethanol concentrations were used for dehydration (gradient elution using 50, 70, 80, 90 and $100 \%$ ethanol with each concentration for $10-15$ minutes and $100 \%$ ethanol three times). Tert-butanol was used for dehydration two times. Pollen was dried using JEOL freeze dryer (JEOL Ltd., Tokyo), spread evenly on the sample stage, stuck with double-sided adhesive tape, and coated with gold in a sputter coater. Pollen grains were photographed at different magnifications, according to the working rules of SEM JSM-6380LV (JEOL Ltd., Tokyo) in the conditions of low vacuum $(P=60 \mathrm{~Pa}$ ) under the following zooming specifications: 3000 times - during the measurements and 15000 times - while taking the pictures of the exine ornamentation features.

Table 1. Origin, flesh color and pollen morphological characters of 17 papaya cultivars

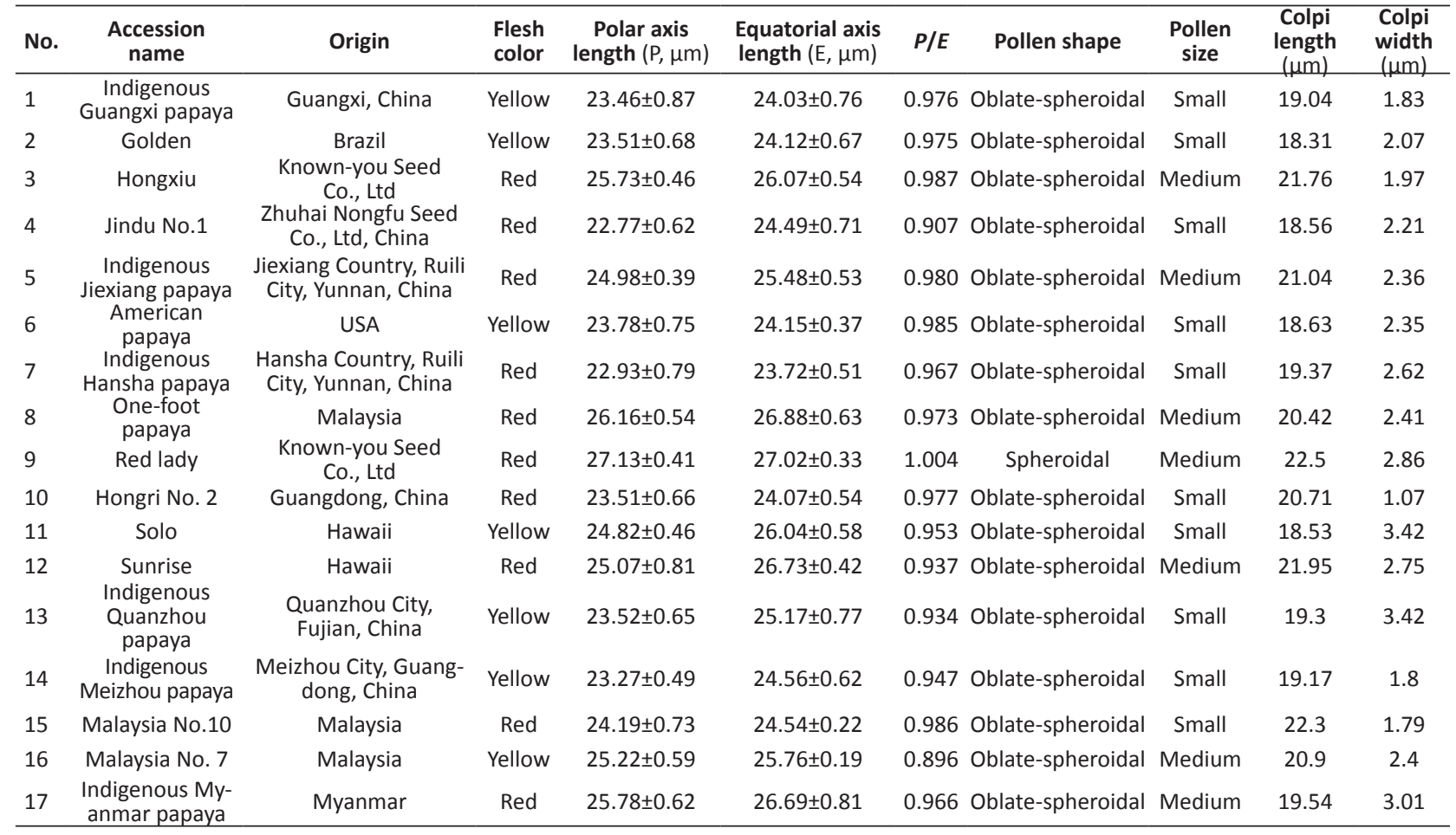


Table 2. Variation of quantitative characters of pollen

\begin{tabular}{lcccc}
\hline Quantitative characters & Range & Mean & Standard deviation & Coefficient of variation (\%) \\
\hline Polar axis length $(P, \mu \mathrm{m})$ & $22.77-27.13$ & 24.46 & 1.23 & 5.0 \\
Equatorial axis length $(\mathrm{E}, \mu \mathrm{m})$ & $23.72-27.02$ & 25.27 & 1.11 & 4.4 \\
Ratio of polar axis length to equatorial axis length $(\mathrm{P} / \mathrm{E})$ & $0.896-1.00$ & 0.96 & 0.03 & 2.9 \\
Colpi length $(\mu \mathrm{m})$ & $18.31-22.50$ & 20.12 & 1.38 & 6.9 \\
Colpi width $(\mu \mathrm{m})$ & $1.07-3.42$ & 2.37 & 0.59 & 25.0 \\
\hline
\end{tabular}

Table 3. Frequency and Shannon diversity index of qualitative characters of pollen

\begin{tabular}{|c|c|c|c|c|}
\hline \multirow{2}{*}{ Qualitative characters } & \multirow{2}{*}{$\begin{array}{c}\text { Shannon diversity } \\
\text { index }\end{array}$} & \multicolumn{3}{|c|}{ Coding frequency (\%) } \\
\hline & & 1 & 2 & 3 \\
\hline Aperture membrane & 1.018 & $\begin{array}{c}\text { Finely granulate } \\
0.235\end{array}$ & $\begin{array}{l}\text { Granulate } \\
0.235\end{array}$ & $\begin{array}{c}\text { Coarsely granulate } \\
0.530\end{array}$ \\
\hline Exine ornamentation & 0.874 & $\begin{array}{c}\text { Foveolate } \\
0.647\end{array}$ & $\begin{array}{c}\text { Reticulate } \\
0.118\end{array}$ & $\begin{array}{c}\text { Fossulate } \\
0.235\end{array}$ \\
\hline Ridge width on tectum & 1.037 & $\begin{array}{c}\text { Narrow } \\
0.176\end{array}$ & $\begin{array}{l}\text { Medium } \\
0.412\end{array}$ & $\begin{array}{l}\text { Wide } \\
0.412\end{array}$ \\
\hline Ridge depth on tectum & 0.804 & $\begin{array}{l}\text { Shallow } \\
0.706\end{array}$ & $\begin{array}{l}\text { Medium } \\
0.118\end{array}$ & $\begin{array}{l}\text { Deep } \\
0.176\end{array}$ \\
\hline Foveola size & 0.894 & $\begin{array}{l}\text { Small } \\
0.648\end{array}$ & $\begin{array}{l}\text { Medium } \\
0.176\end{array}$ & $\begin{array}{l}\text { Large } \\
0.176\end{array}$ \\
\hline Foveola density & 1.037 & $\begin{array}{c}\text { Few } \\
0.412\end{array}$ & $\begin{array}{c}\text { Medium } \\
0.412\end{array}$ & $\begin{array}{l}\text { Abundant } \\
0.176\end{array}$ \\
\hline
\end{tabular}

Pollen descriptions and terminology followed the criteria of Punt et al. (2007) and Hesse et al. (2009). Polar axis length, equatorial axis length, P/E ratio, colpi length, and colpi width were determined in 20 randomly selected pollen grains. Variation of quantitative characters was shown in Table 2 and frequency and Shannon diversity index of qualitative characters was showed in Table 3. Cluster analysis was performed using SPSS 20.0 for genetic relations based on unweighted pair-group method with arithmetic means (UPGMA), wherein averages are weighted by the number of taxa in each cluster at each step, and each distance contributes equally to the final result.

\section{RESULTS AND DISCUSSION}

Studies on pollen morphological characters of cultivars through SEM have proved to be indispensable in the characterization and evaluation of genetic resources (Ayaz et al. 2020, Gul et al. 2021, Horčinová Sedláčková et al. 2021, Ullah et al. 2021).

In the present study, we examined in detail pollen characters of 17 papaya cultivars to highlight the importance of pollen in analyzing diversity of pollen and genetic relationship among cultivars. Papaya was eurypalynous. Papaya pollen grains were monads, isopolar, and radially symmetric (Figures 1 1a-5a, 2 1a-5a, 3 1a-5a, 4 1a-5a). All pollen grains of 17 papaya cultivars were small to medium-sized with diameter ranging from 15 to $40 \mu \mathrm{m}$ (Figures 1 b-5b, 2 1b-5b, 3
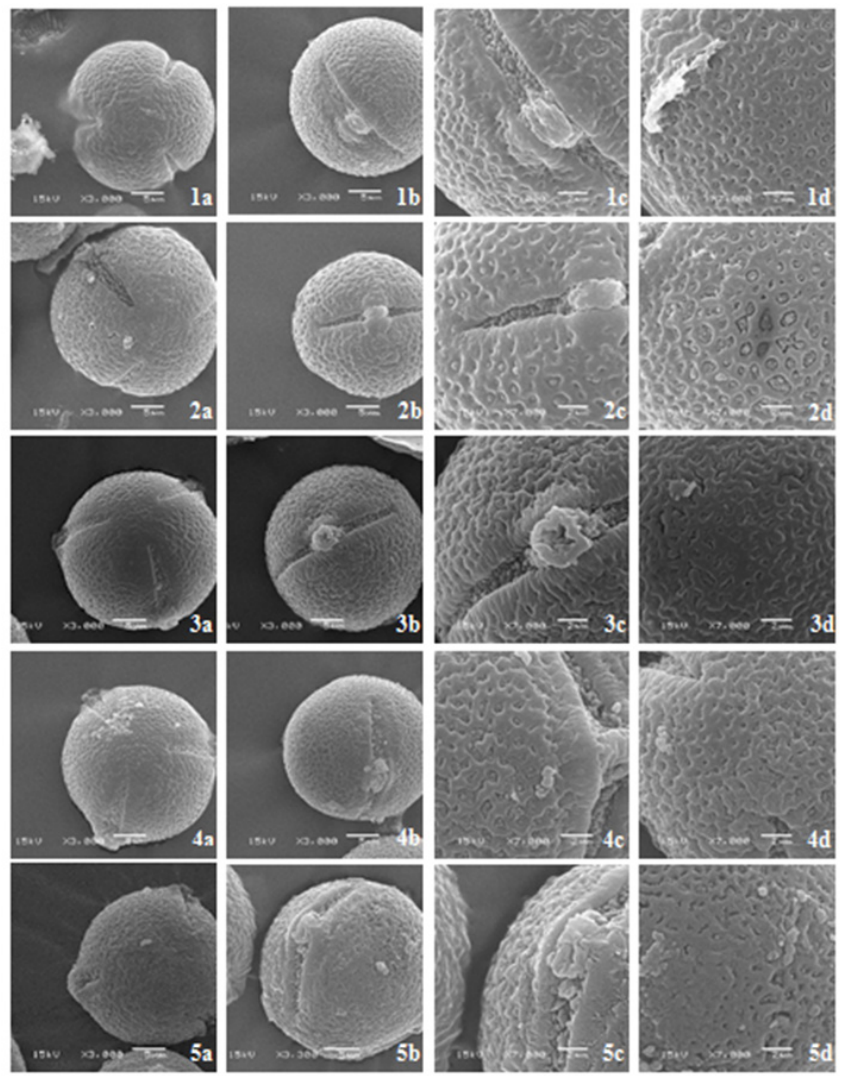

Figure 1. Pollen morphological characters of five papaya cultivars (1. Indigenous Guangxi papaya, 2. Golden, 3. Hongxiu, 4. Jindu No.1, 5. Indigenous Jiexiang papaya). a. Polar view $(3000 \times)$, b. equatorial view $(3000 x)$, c. colporate $(7000 x)$, d. exine ornamentation $(7000 \times)$. 


\section{Y Zhang et al.}

1b-5b, $41 \mathrm{~b}-5 \mathrm{~b}$ ). Polar view was circular (Figures 1 1a5a, 2 1a-5a, 3 1a-5a, 4 1a-5a) and equatorial view was subcircular (Figures 1 1b-5b, 2 1b-5b, 3 1b-5b, 4 1b-5b). Pollen shapes were oblate-spheroidal to spheroidal (Table 1). Papaya pollen grains were zonoaperturate with three colpori (Figures 1 1a-5a, 2 1a-5a, 3 1a-5a, 4 1a-5a). Fisher (1980), Phuangrat et al. (2013) and Zini et al. (2018) also showed that pollen grains were tricolporate, isopolar, radiosymmetric, small- and medium-sized, and spheroidal.

The colpori were situated equatorially and evenly, and had coarsely membrane (Figures $11 b-5 b, 21 b-5 b$, $31 b-5 b, 41 b-5 b)$. Endoaperture was in the center of the colpi (Figures 1 1b-5b, 2 1b-5b, 3 1b-5b, 4 1b-5b). Colpus membrane was uneven with coarsely irregular granules and colpi margin was uneven with granules (Figures 1 1c-5c, 2 1c-5c, 3 1c-5c, 4 1c-5c).

Phuangrat et al. (2013) observed reticulate exine ornamentation at $2500 \times$. In our studies, foveolate, reticulate, and fossulate exine ornamentation were observed at $7000 \times$. 'Indigenous Hansha papaya' showed reticulate exine ornamentation (Figure $22 \mathrm{~d}$ ); 'Jindu No.1' (Figure 14d), 'Indigenous Jiexiang papaya' (Figure $15 \mathrm{~d}$ ), 'Hongri No.2' (Figure $25 \mathrm{~d}$ ) and 'Solo' (Figure 3 1d) showed fossulate exine ornamentation, and other cultivars showed foveolate exine ornamentation. Phuangrat et al. (2013) observed reticulate exine ornamentation. It could be explained that an accurate description of pollen exine ornamentation depends on the magnification (Halbritter et al. 2018).
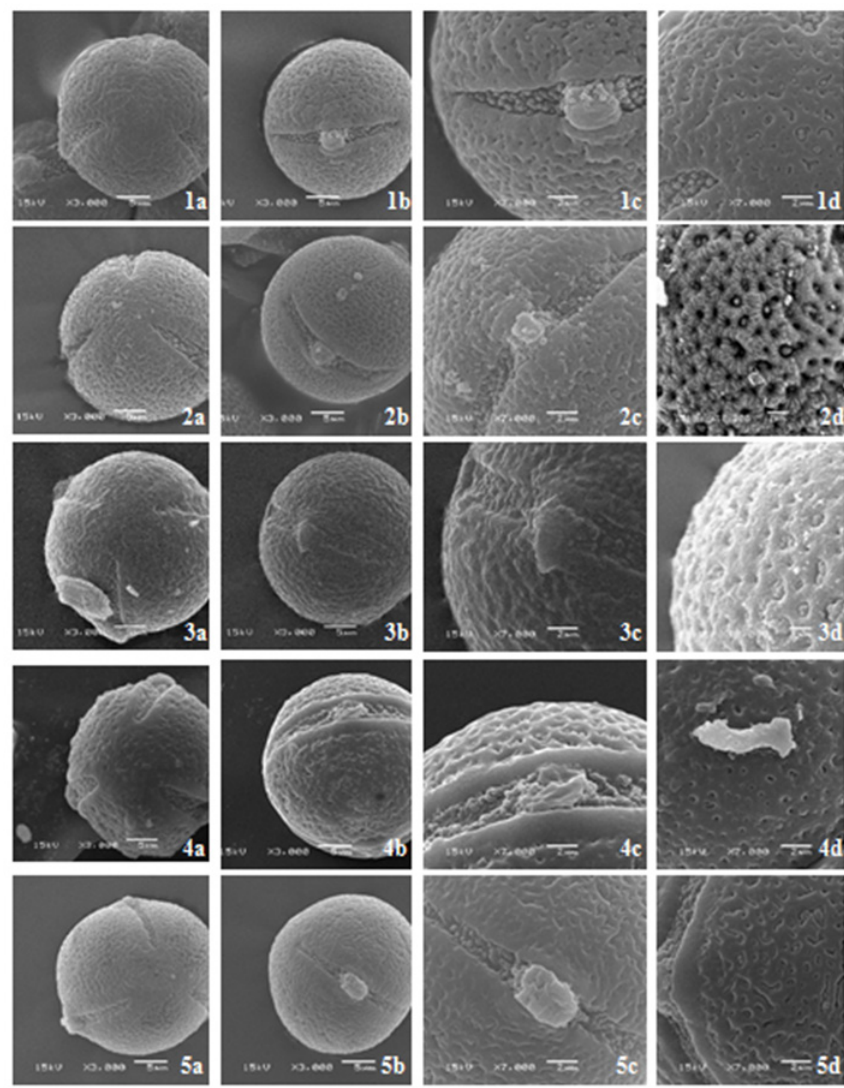

Figure 2. Pollen morphological characters of five papaya cultivars (1. American papaya, 2. Indigenous Hansha papaya, 3. One-foot papaya, 4. Red lady, 5. Hongri No. 2). a. Polar view (3000x), b. equatorial view $(3000 \times)$, c. colporate $(7000 \times)$, d. exine ornamentation $(7000 \times)$.

Our study also provided other pollen characters of papaya shown in Tables 2 and 3, including polar and equatorial axis length, ratio of polar to equatorial axis length, colpi length and width, aperture membrane, ridge width and depth on tectum, and foveola size and density. Pollen characters were first introduced to conduct the genetic diversity analysis of papaya cultivars. Colpi width had maximum coefficient of variation, reaching $25.0 \%$, whereas other quantitative characters had less than $10 \%$ of coefficient of variation. Ma et al. (2015) believed that one character with more than $100 \%$ of coefficient of variation had a strong level of variation, one character with coefficient of variation between $10 \%$ and $100 \%$ had a medium-level variation, and one character with less than $10 \%$ of coefficient of variation had a weak-level variation. Significantly, colpi width had maximum coefficient of variation, reaching $25.0 \%$ in our study, representing a medium-level variation, and could be an important indicator in further pollen morphological analysis of papaya.

Over $50 \%$ of the cultivars were coarsely granulate, $82.4 \%$ cultivars had medium and wide exine ridge, $70.6 \%$ of the cultivars had shallow exine ridge, $64.8 \%$ cultivars had small foveola on exine, and $82.4 \%$ of the cultivars had few or medium foveola. Shannon diversity index ranged from 1.037 (Ridge width on tectum and foveola density) to 0.804 (Ridge depth on tectum), and all qualitative characters reached over 0.8 , showing high genetic diversity that could be helpful in the evaluation and characterization of papaya cultivars.

Our study is one of the first reports on cluster analysis based on pollen characters of papaya. Cluster analysis revealed three groups (G1-G3) (Figure 5). G3 was the largest group, comprising 'Indigenous Guangxi papaya', 'Golden', 'Jindu No.1', 'American papaya', 'Hongri No. 2', 'Indigenous Meizhou papaya' and 'Malaysia No.10'. 'Hongri No. 2' was closely related to 'Malaysia No.10'; 'Jindu No.1' was closely related to 'Indigenous Meizhou papaya'; 'Golden' was closely related 
to 'American papaya'; 'Indigenous Guangxi papaya', 'Golden' and 'American papaya' were in a subgroup. The secondlargest group was G1, and it comprised 'Indigenous Jiexiang papaya', 'One-foot papaya', 'Red lady', 'Sunrise', 'Malaysia No. 7' and 'Indigenous Myanmar papaya'. 'Indigenous Jiexiang papaya' was closely related to 'Malaysia No. 7'; 'One-foot papaya' was closely related to 'Indigenous Myanmar papaya'; 'Red lady' was closely related to 'Sunrise', being accordant with RAPD analysis of Huang et al. (2007). SRAP and SCot analysis also showed that 'Red lady' and 'Sunrise' were clustered into a subgroup with 'Hawaii' (Cai et al. 2014). 'Red lady' is a hybrid from Known-you Seed Co., Ltd, Taiwan and 'Sunrise' is a Hawaii hybrid. Our results were accordant with previous results (Huang et al. 2007, Cai et al. 2014). The smallest group, G2, included 'Hongxiu', 'Indigenous Hansha papaya', 'Solo' and 'Indigenous Quanzhou papaya'. 'Hongxiu' was used as the basis in G2, and 'Indigenous Hansha papaya' was closely related to 'Indigenous Quanzhou papaya'.

In our study, there were ten cultivars with red flesh and seven cultivars with yellow flesh. They could not be clustered distinctly. This is not accordant with the results of Aikpokpodion (2012), who reported that accessions with yellow flesh could be distinct from that with red flesh. There might be two reasons: papaya cultivars in our study were from several countries and not included accessions from Nigeria, while papaya accessions in the study of Aikpokpodion (2012) were from Nigeria. Notably, flesh color of papaya is caused by carotenoid accumulation, and does not follow the rule of dominant inheritance (Pecker et al. 1996).

Papaya cultivars from different origins were not clustered. There are two explanations. First, it showed the complexity of papaya's genetic background, and the genetic introgression of papaya clearly existed. Indigenous China cultivars could not be separated from foreign cultivars. It proved that indigenous China cultivars had close genetic relations and high frequency of germplasm exchange with foreign cultivars. It could be disadvantageous in breeding and genetic improvement of papaya. Therefore, it is essential to explore and introduce more foreign papaya genetic resources in China for obtaining improved cultivars. Second, our study included seventeen papaya cultivars that originated in China, Thailand, Hawaii, American, Malaysia and Myanmar. We need more papaya germplasms from other origins to further validate cluster groupings based on origins.

This study is one of the first to analyze pollen morphology of papaya with different flesh colors and from different origins under SEM. SEM study of papaya pollen plays an important role in the analysis of pollen diversity and genetic relationship among papaya cultivars. Cluster analysis can provide some helpful
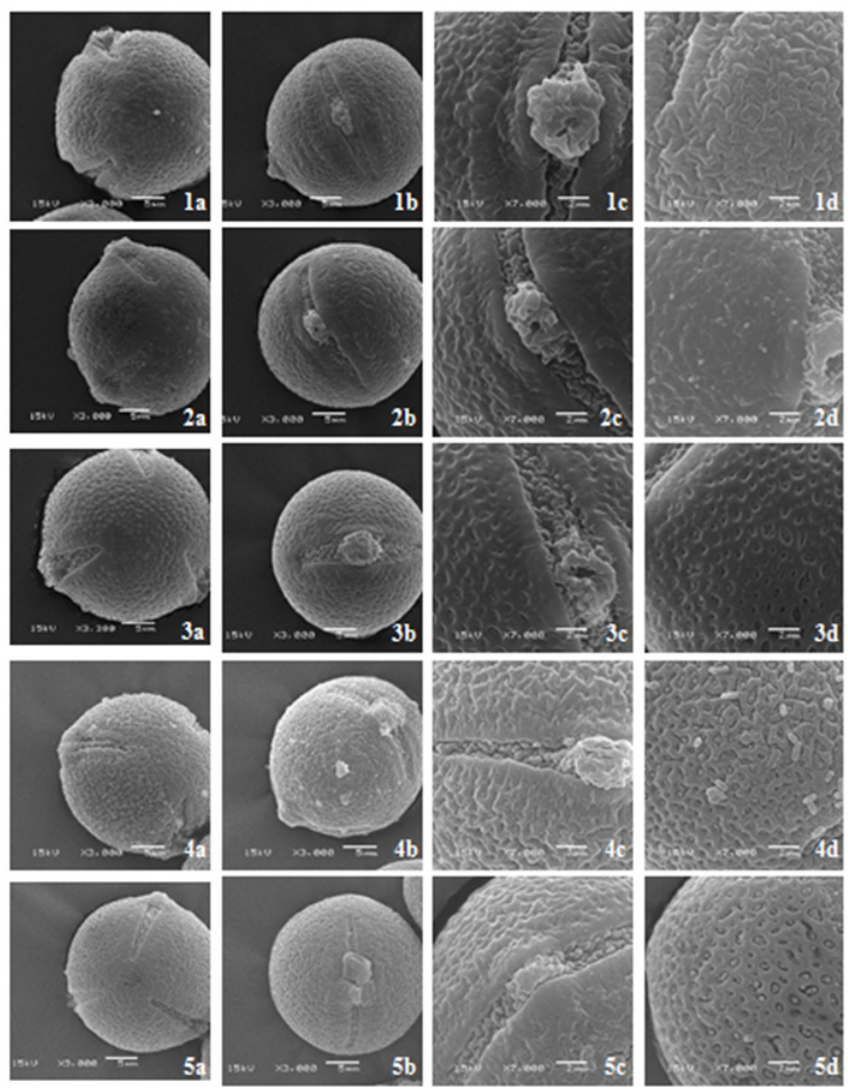

Figure 3. Pollen morphological characters of five papaya cultivars (1. Solo, 2. Sunrise, 3. Indigenous Quanzhou papaya, 4. Indigenous Meizhou papaya, 5. Malaysia No.10). a. Polar view (3000x), b. equatorial view $(3000 \times)$, c. colporate $(7000 \times)$, d. exine ornamentation (7000x).
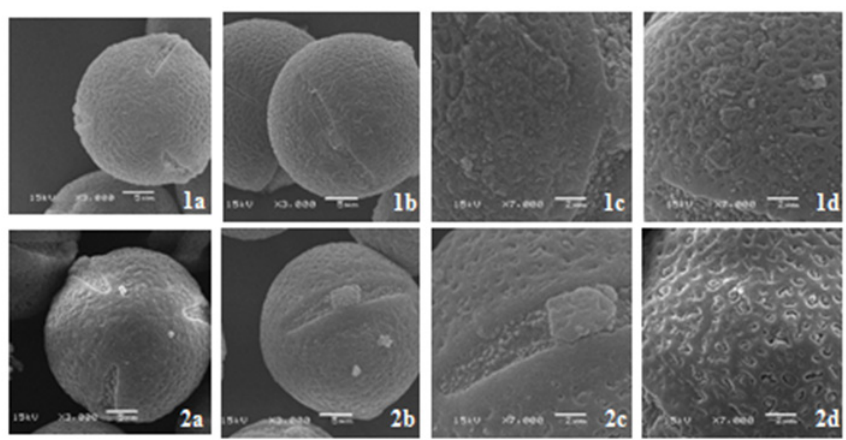

Figure 4. Pollen morphological characters of two papaya cultivars (1. Malaysia No. 7, 2. Indigenous Myanmar papaya). a. Polar view $(3000 x)$, b. equatorial view $(3000 x)$, c. colporate $(7000 x)$, d. exine ornamentation $(7000 \times)$. 


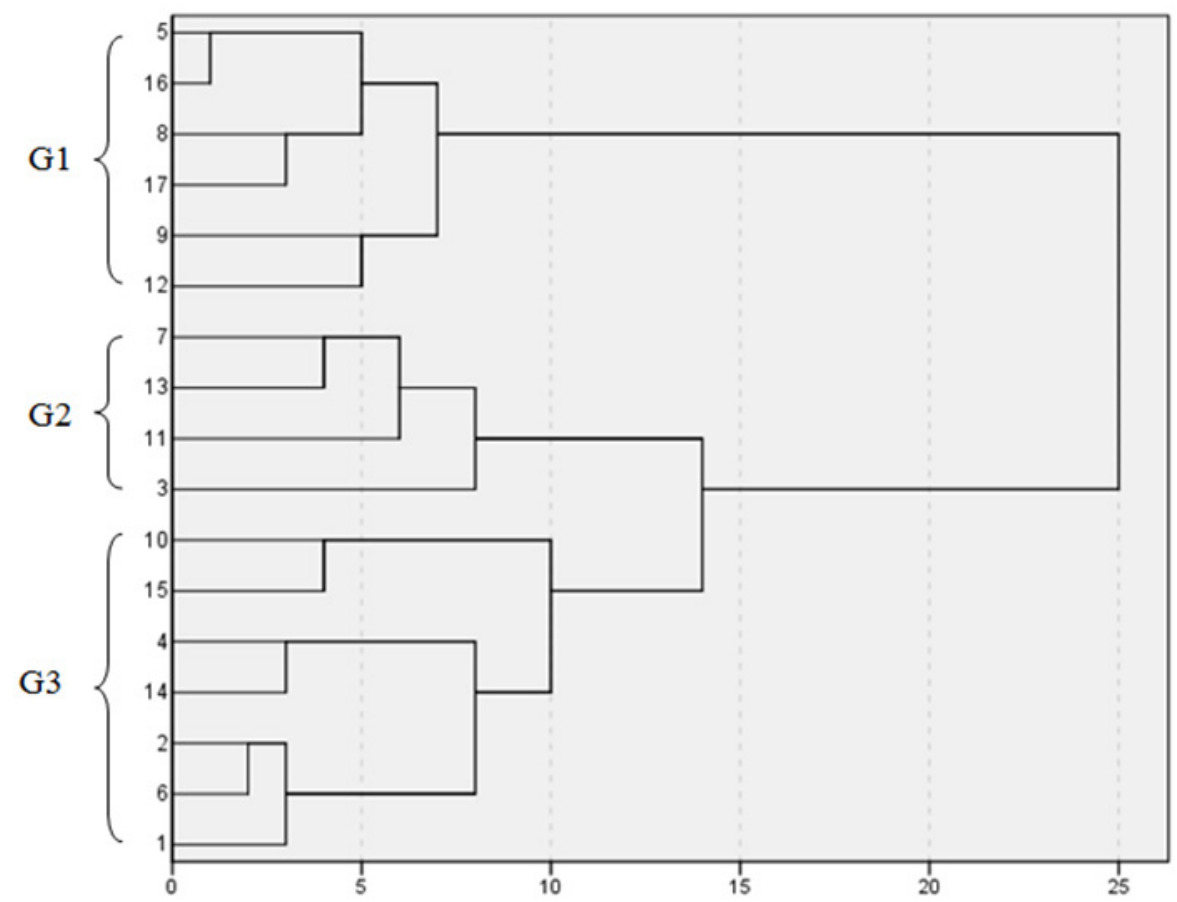

Figure 5. UPGMA dendrogram of pollen morphological characters of 17 papaya cultivars (1. Indigenous Guangxi papaya, 2. Golden, 3. Hongxiu, 4. Jindu No.1, 5. Indigenous Jiexiang papaya, 6. American papaya, 7. Indigenous Hansha papaya, 8. One-foot papaya, 9. Red lady, 10. Hongri No. 2, 11. Solo, 12. Sunrise, 13. Indigenous Quanzhou papaya, 14. Indigenous Meizhou papaya, 15. Malaysia No.10, 16. Malaysia No. 7, 17. Indigenous Myanmar papaya).

information on exploration and identification of papaya genetic resources and on genetic improvement. Moreover, pollen morphological analysis through SEM is relatively easy and cost-effective compared with molecular and genomic analysis.

\section{ACKNOWLEDGEMNTS}

This work was supported by Basic Scientific Research Funds of Public Welfare Scientific Research Institutes of Fujian Province (2020R1028007), Fujian Innovation base of papaya Germplasm Resources Protection, Germplasm Resources Protection Project of Ministry of Agriculture of the People's Republic of China (16RZZY-32), and Germplasm Resources Protection Project of Ministry of Agriculture and Rural Affairs of the People's Republic of China (1518213013540527016). We would like to thank Editage (www.editage.cn) for English language editing.

\section{REFERENCES}

Aikpokpodion PO (2012) Assessment of genetic diversity in horticultural and morphological traits among papaya (Carica papaya) accessions in Nigeria. Fruits 67: 173-187.

Ayaz A, Zaman W, Ullah F, Saqib S, Jamshed S, Bahadur S, Shakoor A and Arshad B (2020) Systematics study through scanning electron microscopy; a tool for the authentication of herbal drug Mentha suaveolens Ehrh. Microscopy Research \& Technique 83: 81-87.

Cai YB, Yang XY, Chen HJ, Zeng LM, Pang XH and Sun GM (2014) Genetic diversity analysis of papaya resources by SRAP and ScoT combination. Journal of Plant Genetic Resource 15: 292-298.

Damasceno Junior PC, Pereira TNS and Pereira MG (2018) Estimation of genetic parameters for flower anomalies in papaya. Crop Breeding and Applied Biotechnology 18: 9-15.

Erdtman G (1952) Pollen morphology and plant taxonomy-Angiosperms: an introduction to palynology. Almqvisit \& Wiksell, Stockholm, 539p.

Fang JP, Wood A, Chen RK and Ming R (2016) Molecular basis of off-type microsatellite markers in papaya. Euphytica 209: 323-339.

Fisher JB (1980) The vegetative and reproductive structure of papaya (Carica papaya). Lyonia 1: 191-208.

Gul S, Ahmad M, Zafar M, Bahadur S, Zaman W, Ayaz A, Shuaib M, Butt MA, Ullah F, Saqib S, Nizamani MM and Urooj Z (2021) Palynological characteristics of selected Lamioideae taxa and its taxonomic significance. Microscopy Research \& Technique 84: 471-479. 
Halbritter H, Ulrich S, Grímsson F, Weber M, Zetter R, Hesse M, Buchner R, Svojtka M and Frosch-Radivo A (2018) Illustrated pollen terminology. $2^{\text {nd }}$ edn, Springer Open, Cham, 487p.

Hesse M, Halbritter H, Zetter R, Weber M, Buchner R, Frosch-Radivo A and Ulrich S (2009) Pollen terminology, an illustrated handbook. SpringerWien, New York, 55p.

Horčinová Sedláčková V, Grygorieva O and Gurnenko I (2021) Study of morphological characters of pollen grains sweet chestnut (Castanea sativa Mill.) by scanning electron microscopy. Agrobiodiversity for Improving Nutrition, Health and Life Quality 5: 116-125.

Huang JC, Ren CX, Li L and Xiao Y (2007) RAPD analysis of 17 papaya cultivars/lines. Journal of Southwest University (Natural Science Edition) 29: 91-94.

Jurandi GO, Luis MMM, Willian BS, Aroldo GF and Rober EP (2018) Papaya. In Freitas ST and Sunil Pareek (eds) Postharvest physiological disorders in fruits and vegetables (Innovations in postharvest technology series). CRC Press, Boca Raton, p. 399-421.

Kumari S and Mishra M (2019) Papaya (Carica papaya L.). In Aswath C, Parthasarathy VA, Sanjay Kumar Singh and Vinoth S (eds) Breeding of horticultural crop vol 2: tropical fruits. Today \& Tomorrow's Printes and Publishers, New Delhi, p. 339-360.

Liao ZY, Yu QY and Ming R (2017) Development of male-specific markers and identification of sex reversal mutants in papaya. Euphytica 213: 53 .

Lucas Luz LN, Santa-Catarina R, Barros GB, Barros FR, Vettorazzi JCF and Pereira MG (2018) Adaptability and stability of papaya hybrids affected by production seasonality. Crop Breeding and Applied Biotechnology 18: 357-364.

Lynn A, Piotter E, Harrison E and Galen C (2020) Sexual and natural selection on pollen morphology in Taraxacum. American Journal of Botany 107: 1-11.

Ma RL, Jiao YS, Cheng Y and Qiao N (2015) Analysis on genetic diversity of pepper resources based on phenotypic traits. Journal of Shanxi Agricultural Sciences 43: 1577-1581.

Ming R, Yu QY, Moore PH, Paull RE, Chen NJ, Wang ML, Zhu YJ, Schuler MA, Jiang JM and Paterson AH (2012) Genome of papaya, a fast growing tropical fruit tree. Tree Genetics and Genomes 8: 445-462.

Palei S, Rout GR and Dash DK (2019) Molecular and morphological assessment of papaya (Carica papaya). Research Journal of Biotechnology 14: 63-70.

Pan ZJ, Chen HJ, Zhou QG and Gan WT (2011) Comparative analysis of different Carica papaya L. lines. Journal of Southern Agriculture 42: 958-960.

Payamnoor V, Sattarian A, Kordalivand A and Mohammadi J (2019) Pollen morphology and trichome types of Betula spp. in the Hyrcanian forests of northern Iran. Journal of Forest Research 30: 1191-1198.
Pecker I, Gabbay R, Cunningham FX and Hirschberg J (1996) Cloning and characterization of the cDNA for lycopene beta-cyclase from tomato reveals decrease in its expression during fruit ripening. Plant Molecular Biology 30: 807-819.

Phuangrat B, Phironrit N, Son-ong A, Puangchon P, Meechai A, Wasee S, Kositratana W and Burns P (2013) Histological and morphological studies of pollen grains from elongata, reduced elongata and staminate flowers in Carica papaya L. Tropical Plant Biology 6: 210-216.

Punt W, Hoen PP, Blackmore S, Nilsson S and Le Thomas A (2007) Glossary of pollen and spore terminology. Review of Paleobotany and Palynology 143: 1-81.

Santos LMS, Pereira TNS, de Souza MM, Damasceno Junior PC, Costa FR, Ribeiro BF, Freitas NG and Pereira MG (2008) Optical and ultrastructural study of the pollen grain development in hermaphrodite papaya tree (Carica papaya L.). Brazilian Archices of Biology and Technology 51: 539-545.

Silva-Fourny AC, Hollunder RK, Garbin ML, Carrijo TT, Mendonça CBF and Gonçalves-Esteves V (2020) Pollen morphology applied to species delimitation of Myrsine (Myrsinoideae- Primulaceae). Plant Systematics and Evolution 306: 21.

Singh A, Singh G, Kalia A, Rattanpal HS and Gupta M (2020) Leaf morphoanatomical diversity analysis in mandarin (Citrus reticulata Blanco) genotypes using scanning electron microscopy. Genetic Resources and Crop Evolution 67: 2173-2194.

Srivastava AK and Singh VK (2016) Carica papaya - A herbal medicine. International Journal of Research Studies in Biosciences 4: 19-25.

Ullah F, Ayaz A, Saqib S, Parmar G, Bahadur S and Zaman W (2021) Taxonomic implication of leaf epidermal anatomy of selected taxa of Scrophulariaceae from Pakistan. Microscopy Research \& Technique 84: 521-530.

van Droogenbroeck B, Breyne P, Goetghebeur P, Romeijn-Peeters E, Kyndt T and Gheysen G (2002) AFLP analysis of genetic relationships among papaya and its wild relatives (Caricaceae) from Ecuador. Theoretical and Applied Genetics 105: 289-297.

Wu Y, Chen QX and Ling YF (2011) Cultivation and adaptability of papaya species from Taiwan in Zhangzhou area. Fujian Journal of Agricultural Sciences 26: 83-86.

Xiong YM, Liu YJ and Huang XF (2015) Main characteristics and evaluation of 12 papaya germplasms. South China Fruits 44: 118-120.

Xiong YM, Liu YJ and Huang XF (2019) Main characteristics and evaluation of 68 papaya germplasms. China Fruits 2: 83-88.

Zini LM, Carrera CS, Lattar EC and Ferrucci MS (2018) Pollen morphology in selected species of caricaceae with special reference to novel palynological characters. Botany 96: 1-8.

(cc) EY This is an Open Access article distributed under the terms of the Creative Commons Attribution License, which permits unrestricted use, distribution, and reproduction in any medium, provided the original work is properly cited. 